\title{
Growth and Photosynthesis of Japanese Flowering Cherry under Simulated Microgravity Conditions
}

\author{
Mami Sugano ${ }^{1}$, Yoshio Ino² and Teruko Nakamura ${ }^{1}$ \\ ${ }^{1}$ Graduate School of Science, Japan Women's University, 2-8-1 Mejirodai, Bunkyo-ku, Tokyo 112-8681, Japan \\ ${ }^{2}$ Department of Biology, School of Education, Waseda University, Nishiwaseda, Shinjuku-ku, Tokyo 169-8050, Japan
}

\begin{abstract}
The photosynthetic rate, the leaf characteristics related to photosynthesis, such as the chlorophyll content, chlorophyll $a / b$ ratio and density of the stomata, the leaf area and the dry weight in seedlings of Japanese flowering cherry grown under normal gravity and simulated microgravity conditions were examined. No significant differences were found in the photosynthetic rates between the two conditions. Moreover, leaf characteristics such as the chlorophyll content, chlorophyll $a / b$ ratio and density of the stomata in the seedlings grown under the simulated microgravity condition were not affected. However, the photosynthetic product of the whole seedling under the simulated microgravity condition increased compared with the control due to its leaf area increase. The results suggest that dynamic gravitational stimulus controls the partitioning of the products of photosynthesis.
\end{abstract}

Key words: 3D-clinostat, growth, Japanese flowering cherry, photosynthesis, simulated microgravity

\section{Introduction}

Previously we showed that stems grew bent, stem elongation and leaf expansion both increased, and the formation of xylem in the secondary thickening growth was inhibited in Japanese flowering cherry under simulated microgravity conditions (Nakamura et al., 1999). In this study, we examined whether gravity affects photosynthesis in Japanese flowering cherry under simulated microgravity conditions by means of a 3D-clinostat (Yamada et al., 1993; Yamashita et al., 1997).

\section{Materials and Methods}

Seedlings of Japanese flowering cherry, Prunus jamasakura Siebold ex Koids., were used as the plant material. The seedlings were grown for 4 weeks in pots containing a mixture of Jiffy 7 (Jiffy Products Ltd., Norway) and vermiculite on earth (control plants) and on a 3Dclinostat (3D-clinorotated plants). The 3D-clinostat is a device that simulates microgravity (Yamada et al., 1993; Yamashita et al., 1997). The rotation rate of the 3D-clinostat was controlled by a computer at 1 to -1 (reverse direction) $\mathrm{rpm}$. The seedlings were cultured under continuous light of $70 \mu \mathrm{mol} \mathrm{m} \mathrm{m}^{-2} \mathrm{~s}^{-1}$ of photon flux density (PFD) at $22^{\circ} \mathrm{C}$ and at $70 \%$ relative humidity.

A LI-Cor LI6400 portable photosynthesis measurement system (LI-Cor. Inc., USA) was used to measure photosynthesis of leaves directly. Photosynthesis was

\footnotetext{
Original papers

Received December 5, 2002

Accepted December 20, 2002

Address for correspondence: Teruko Nakamura Graduate School of Science, Japan Women's University, 2-8-1 Mejirodai, Bunkyo-ku, Tokyo 112-8681, Japan E-mail: teruko-n@fc.jwu.ac.jp
}

measured by the $\mathrm{CO}_{2}$ uptake of the intact fourth leaf, the youngest expanded leaf. After removing the $\mathrm{CO}_{2}$ from the air of the measurement chamber with soda lime, pure $\mathrm{CO}_{2}$ gas was added to the measurement chamber up to $360 \mathrm{ppm}$ in volume. The temperature and the humidity in the measurement chamber were kept at $22^{\circ} \mathrm{C}$ and $50 \%$, respectively. The photosynthetic rate was measured at 7 levels of PFD, i.e., 1000, 750, 500, 200, 100, 50 and 0 umol m $\mathrm{m}^{-2} \mathrm{~s}^{-1}$.

Chlorophyll was extracted from part of the fourth leaf with $80 \%$ acetone, and the concentrations of chlorophyll $a$ and $b$ were determined spectrophotometrically using the equations of Porra et al. (1989). The epidermis on the back of the fourth leaf was peeled off, and the density of its stomata was measured by light microscopy. The measured samples were separated into leaves with petioles, stems and roots, then dried at $-20^{\circ} \mathrm{C}$ in a freeze-drier for measurement of the dry weight. Each leaf was placed on a clear sheet and copied before drying to measure the leaf area. The leaf area was analyzed using the public domain NIH Image program (developed at the U.S. National Institutes of Health) on a Macintosh computer.

\section{Results}

Photosynthetic rates were saturated at greater than 200 $\mu \mathrm{mol} \mathrm{m} \mathrm{m}^{-2} \mathrm{~s}^{-1}$ of PFD in both the control and the 3Dclinorotated plants. The maximum photosynthetic rate by leaf area was 2.1-4.3 $\mu \mathrm{mol} \mathrm{CO}_{2} \mathrm{~m}^{-2} \mathrm{~s}^{-1}$, and that by the chlorophyll content was 5.5-13 $\mu \mathrm{mol} \mathrm{CO}_{2} \mathrm{~g}_{\text {chlorophyll }}{ }^{-1}$ $\mathrm{s}^{-1}$ in the control plants. In the $3 \mathrm{D}$-clinorotated plants, the maximum photosynthetic rate by leaf area was 2.1-5 $\mu \mathrm{mol}$ $\mathrm{CO}_{2} \mathrm{~m}^{-2} \mathrm{~s}^{-1}$, and that by the chlorophyll content was 5.4$19 \mu \mathrm{mol} \mathrm{CO} \mathrm{g}$ chlorophyll $^{-1} \mathrm{~s}^{-1}$. Figure 1 shows the mean photosynthetic rates at $1000 \mu \mathrm{mol} \mathrm{m} \mathrm{m}^{-2} \mathrm{~s}^{-1}$ of PFD, the maximum value, and those at 50 and $100 \mu \mathrm{mol} \mathrm{m} \mathrm{m}^{-2} \mathrm{~s}^{-1}$ of 
(a)

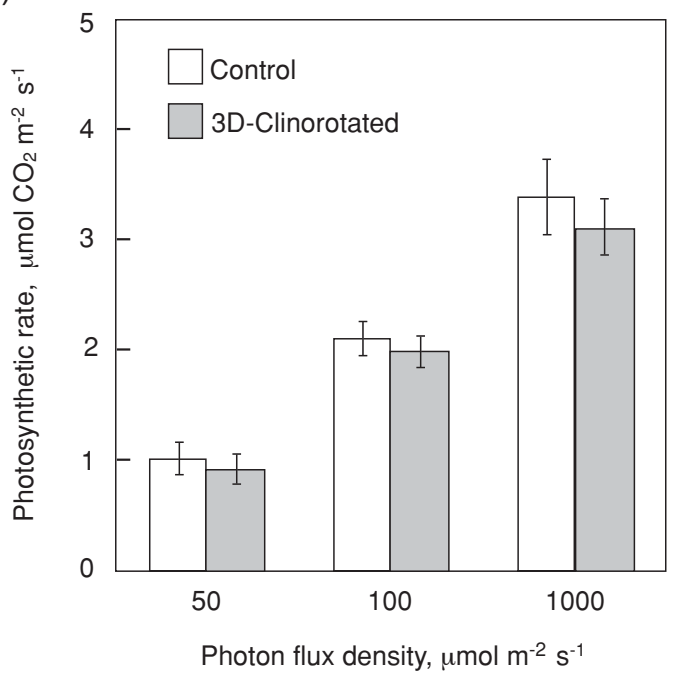

(b)

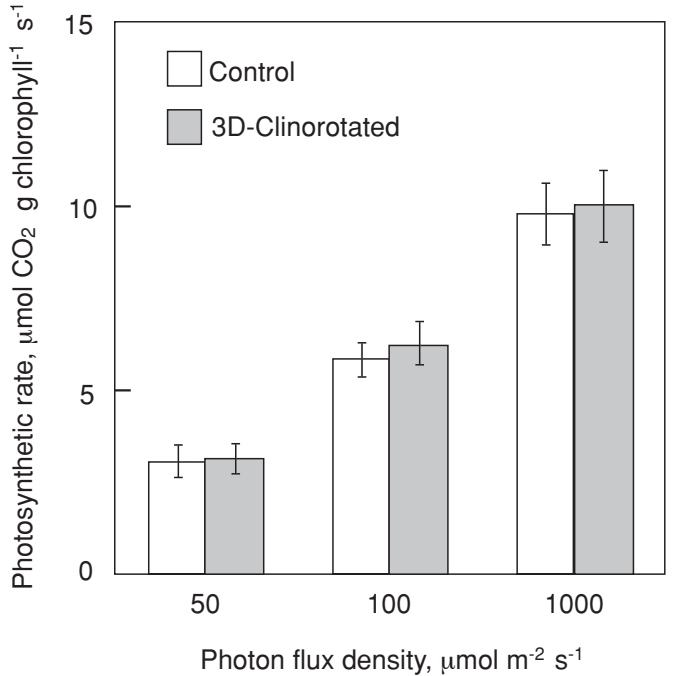

Fig. 1 The mean (a) photosynthetic rate by leaf area and (b) that by the chlorophyll content at 50,100 and $1000 \mu \mathrm{mol} \mathrm{m} \mathrm{m}^{-2} \mathrm{~s}^{-1}$ of photon flux density in control and 3D-clinorotated seedlings. Leaf temperature was $22^{\circ} \mathrm{C}$ and $\mathrm{CO}_{2}$ concentration was $360 \mathrm{ppm}$. The vertical bars indicate $\mathrm{SE}$ ( $\mathrm{n}>10$ ).

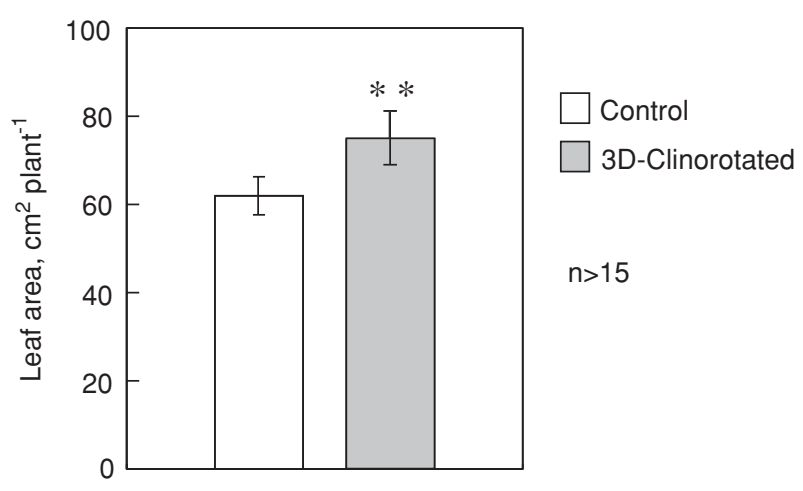

Fig. 2 The leaf area per plant in control and 3D-clinorotated seedlings. The vertical bars indicate $\mathrm{SE}(\mathrm{n}>15)$. ${ }^{* *}$, significant difference at $\mathrm{p}=0.1$ ( $t$-test).

PFD, the values in the near growth condition in the control and the 3D-clinorotated plants. No significant differences were found in the mean photosynthetic rates between the two conditions. Similarly, in both plants the chlorophyll content including chlorophyll $a$ and $b$ was $0.32-0.35 \mathrm{~g} \mathrm{~m}^{-2}$, and the chlorophyll $a / b$ ratio was approximately 3.1 . The stomata density of the leaf was $230-260 \mathrm{~mm}^{-2}$ (Table 1 ). Moreover, the area and the dry weight of leaves in the 3Dclinorotated plants were examined, and both were slightly greater than those in the control plants, although the dry

Table 1 Comparison of leaf characteristics (mean \pm SE) in control and 3D-clinorotated seedlings.

\begin{tabular}{lcc}
\hline & Control & 3D-Clinorotated \\
\hline Chlorophyll $\left(\mathrm{g} \mathrm{m}^{-2}\right)$ & $0.344 \pm 0.019$ & $0.339 \pm 0.043$ \\
Chlorophyll alb & $3.18 \pm 0.04$ & $3.12 \pm 0.05$ \\
Density of stomata $\left(\mathrm{mm}^{-2}\right)$ & $240 \pm 22.1$ & $254 \pm 27.9$ \\
\hline
\end{tabular}

weights of stems and roots were almost the same in both plants (Figs. 2, 3). The dry weight of the whole seedlings grown on the $3 \mathrm{D}$-clinostat was greater than that of the control plants (Fig. 3).

\section{Discussion}

The photosynthetic rate showed no significant difference between the control and 3D-clinorotated plants of Japanese flowering cherry. Moreover, the leaf characteristics that relate to photosynthesis, such as the chlorophyll content, the chlorophyll $a / b$ ratio and the density of the stomata, were also similar in both plants. The present result is supported by the study using the cotyledons of garden cress grown on a 3D-clinostat (Yamada et al., 1993). On the other hand, wheat leaf showed a reduced photosynthetic rate in space-grown plants compared with the control plants (Brown, 2000). The differences in these results might depend on plant species and the conditions of growth and measurement.

The total dry weight of the 3D-clinorotated plants was greater than that of the control plants due to the increased leaf weight in the 3D-clinorotated plants. However, the dry weights of stems and roots in the $3 \mathrm{D}$-clinorotated plants were unchanged. The result suggests that the partitioning of the products of photosynthesis in the 3D-clinorotated plants changed compared with that of the control plant. The leaf area in 3D-clinorotated plants was slightly greater than that in the control plants, and this leaf expansion produced the increase in their dry weight. The dry weight of the stem in the 3D-clinorotated plants was unchanged, whereas we have already reported that stem elongation increased under this condition (Nakamura et al., 1999). The stem elongation in the 3D-clinorotated plants may be due to 


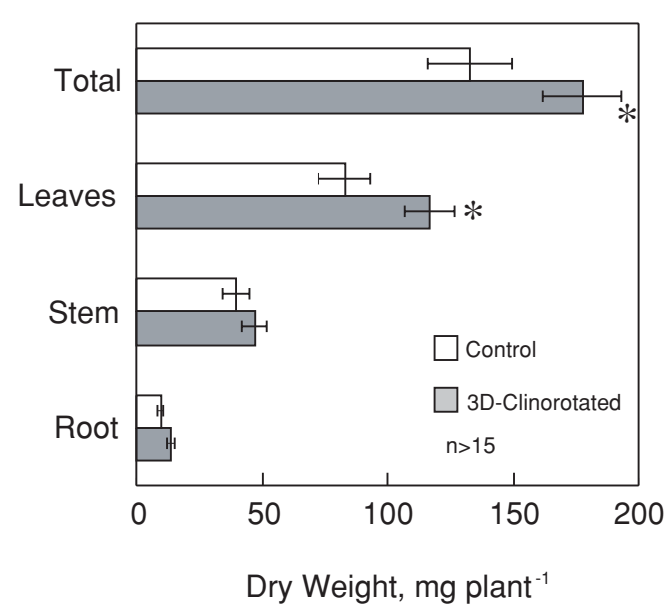

Fig. 3 The dry weights of leaves, stems and roots in control and 3Dclinorotated seedlings. The leaf value includes the petiole. The vertical bars indicate $\mathrm{SE}(\mathrm{n}>10)$. ${ }^{*}$, significant difference at $\mathrm{p}=0.05$ ( $t$-test).

the swelling of the cells. We have also reported that the formation of secondary xylem as the main supporting tissue for upright growth was seriously suppressed in 3Dclinorotated plants (Nakamura et al., 1999). Previous and present results suggest that the dynamic gravitational stimulus controls not only the formation of secondary xylem, but the partitioning of the products of photosynthesis. Further studies in a space experiment to analyze the mechanisms of photosynthesis and the partitioning of the products of photosynthesis are required.

\section{Acknowledgments}

We thank Mr. Tomoyuki Maekawa and Miss Nami Hatsukano for their technical support.

This work was supported in part by Grants-in-Aid from the Ministry of Education, Science, Sports and Culture of Japan (12460070), the Japan Space Forum (B210) and the Institute of Space and Astronomical Science (H13 U29).

\section{References}

Brown, C.S. (2000) Photosynthesis and starch metabolism in space-grown plants. Plants Institute of Genetic Ecology, Tohoku University. pp.75-82. Sendai.

Nakamura, T., N. Sassa, E. Kuroiwa, Y. Negishi, A. Hashimoto, M. Yamashita, and M. Yamada (1999) Growth of Prunus tree stems under simulated microgravity condition. Adv. Space Res., 23, 2017-2020.

Nakamura, T., Y. Negishi, R. Funada, and M. Yamada (2001) Sedimentable amyloplasts in starch sheath cells of woody stems of Japanese cherry. Adv. Space Res., 27, 957-960.

Porra, R. J., W.A. Thompson, and P.E. Kriedemann (1989) Determination of accurate extinction coefficients and simultaneous equations for assaying chlorophyll $a$ and $b$ extracted with four different solvents. Biochimica et Biophysica Acta, 975, 384-394.

Yamada M., Y. Takeuchi, H. Kasahara, S. Murakami, and M. Yamashita (1993) Plant growth under clinostat-microgravity condition. Biol. Sci. Space, 7, 116-119.
Yamashita, M., A. Yamashita, and M. Yamada (1997) Three dimensional (3D-) clinostat and its operational characteristics. Biol. Sci. Space, 11, 112-118 (Abstract in English). 